DOI: $10.5007 / 2175-7941.2013 v 30 \mathrm{n} 2 \mathrm{p} 440$

\title{
COMO QUEIMAR UM PAPEL À LUZ DE SÍRIO+**
}

Guilherme de Almeida

Colégio Militar

Associação Portuguesa de Astrônomos Amadores (APAA)

Lisboa - Portugal

\section{Resumo}

É bem conhecida a experiência de queimar um papel com uma lupa. Será possível, com uma lupa gigantesca, fazer o mesmo utilizando a luz de uma outra estrela? Que requisitos serão necessários? Este artigo aborda as diversas perspectivas sobre o assunto, mostrando as limitações e as possibilidades práticas de tal procedimento. Trata-se de uma exploração conceitual e não de um projeto construtivo.

Palavras-chave: Lentes convergentes. Lupas. Imagem do Sol. Convergência de raios luminosos. Diâmetro da imagem projetada. Concentração de energia. Absorção do fluxo luminoso. Magnitude estelar. Massa. Volume.

\begin{abstract}
Everybody knows the classic experiment of burning a piece of paper using a magnifying glass. Is it possible to do the same using the light of a star and a huge lens? What stuff did we need for that? This article will show different perspectives about that, considering the limitations and practical possibilities for such a procedure. It is just a conceptual exploration, not an engineering project.
\end{abstract}

\footnotetext{
How to burn a piece of paper in the light of Sirius

* Recebido: janeiro de 2012.

Aceito: maio de 2013.
} 
Keywords: Convergent lenses. Magnifying glasses. Image of the Sun. Convergence of light rays. Diameter of the projected image. Energy concentration. Light absorption. Stellar magnitude. Mass. Volume.

\section{Introdução}

Todos nós já experimentamos incendiar um papel utilizando uma lupa. Escassos segundos bastam para fazê-lo, mesmo utilizando uma lupa de tamanho modesto. Que tamanho deveria ter uma lupa capaz de fazer o mesmo utilizando a luz de Sírio ( $\alpha$ Canis Majoris)? Neste artigo, propomo-nos determinar quantitativamente que características deveria ter essa lupa, que se prevê gigantesca. Como é óbvio, trata-se de mera exploração conceitual, pois tal projeto revela-se - como o leitor verá - irrealizável por diversas razões.

\section{A experiência tradicional}

O papel queima devido à intensa concentração dos raios solares na sua superfície. Queima mais rápido se a superfície for escura, por exemplo, uma página de jornal, escolhendo uma zona com uma fotografia. O papel branco demora mais tempo, dado que uma grande parte da energia é refletida e só uma fração dela é que é absorvida pelo papel. É por isso que o papel, caso seja for branco, fica insuportavelmente brilhante quando a convergência se maximiza.

É um erro muito comum pensar que a luz solar, ao atravessar a lente vai convergir em um ponto. Na verdade, a lente produz, no papel, quando se procura a mínima área iluminada, a imagem real do Sol. Se a lente tiver a distância focal $f$, tendo o Sol o diâmetro aparente $\theta$ de cerca de $0,5^{\circ}=0,5 \pi / 180$ radianos $=$ $8,727 \times 10^{-3} \mathrm{rad}$, o diâmetro da imagem solar será

$$
d=f \theta,
$$

com $\theta$ expresso em radianos e $d$ nas mesmas unidades de $f$. Por exemplo, se $f=15 \mathrm{~cm}$, obtemos

$$
d=15 \times 8,7270 \times 10^{-3}=0,13095 \mathrm{~cm} \approx 1,31 \mathrm{~mm} .
$$

Com lentes do mesmo diâmetro e distâncias focais sucessivamente maiores, o diâmetro da imagem solar será cada vez maior e a convergência acabará por ser insuficiente para incendiar o papel. Por exemplo, uma lente de $6 \mathrm{~cm}$ de diâmetro $(D)$ e $15 \mathrm{~cm}$ de distância focal ${ }^{(\mathbf{1})}$ exposta ao Sol consegue incendiar um papel, 
dado que a luz que atravessou a lente cuja área é $A_{1}=\pi \times 3^{2} \approx 28,27 \mathrm{~cm}^{2}$ convergirá em um pequeno círculo de $0,131 \mathrm{~cm}$ de diâmetro, de área muito menor, $A_{2}=\pi(0,0655)^{2} \approx 0,0135 \mathrm{~cm}^{2}$. Neste caso, $A_{1} / A_{2}=28,27 / 0,0135 \approx 2094$. Consegue-se, nesta situação, aumentar a concentração de energia em mais de duas mil vezes.

Entretanto, se uma lente do mesmo diâmetro tiver, por exemplo, $1 \mathrm{~m}$ de distância focal $(100 \mathrm{~cm})$, muito dificilmente incendiará um papel, pois a imagem do Sol por ela produzida no papel terá o diâmetro $d^{\prime}$ dado por

$$
d^{\prime}=100 \times 8,7270 \times 10^{-3}=0,8727 \mathrm{~cm} \approx 8,73 \mathrm{~mm} .
$$

A concentração de energia no papel, na pequena área ocupada pela intensa imagem solar, seria $(60 / 8,73)^{2}=47,24$ vezes superior àquela que chegaria à mesma área de papel sem o auxílio da convergência da lente: daí a maior difículdade em incendiar o papel. Mas se a lente tivesse $2 \mathrm{~m}$ de distância focal (com o mesmo diâmetro), então, o diâmetro da imagem solar seria $2 \times 8,73 \mathrm{~mm}$ e o fator de concentração valeria apenas 11,81: o papel não arderia de modo algum.

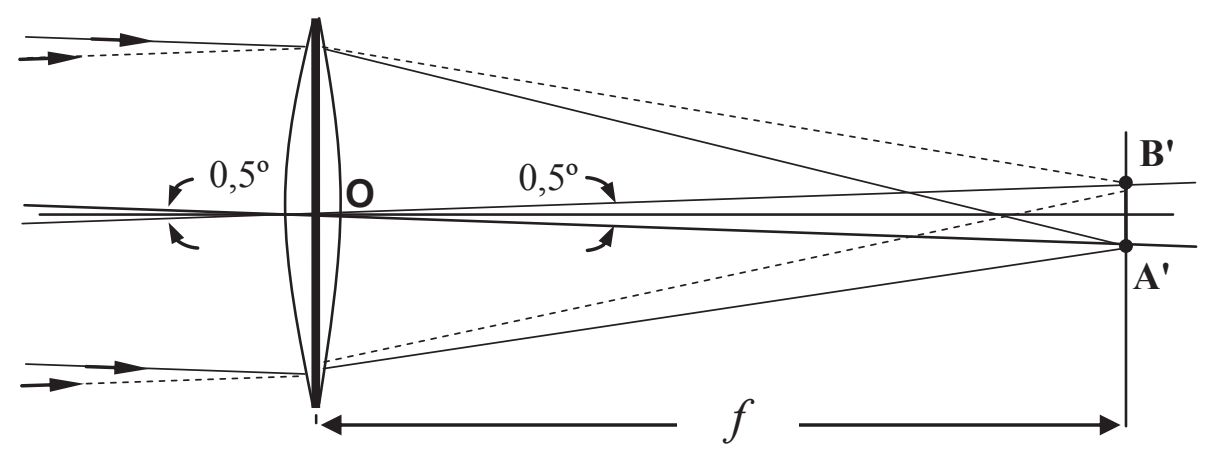

Fig. 1 - Os raios luminosos emitidos do bordo superior do Sol, A, e do bordo inferior, $B$, produzem no plano focal da lente as imagens conjugadas $A^{\prime}$ e $B$ ', respectivamente. A medida do segmento $A B$ é o diâmetro da imagem do Sol. $O$ ângulo $A^{\prime} \hat{O} B^{\prime}$ é, evidentemente, o diâmetro aparente do Sol. Figura de Guilherme de Almeida (2013). 


\section{O caso da estrela Sírio( ${ }^{(2)}$}

Será que, com uma lente adequada, se conseguiria incendiar um papel usando a luz de Sírio? É o que vamos ver. A magnitude aparente de Sírio é $-1,5$ e a do Sol -26,8 (FERREIRA; ALMEIDA, 2004). A razão entre os fluxos luminosos recebidos por unidade de área sobre a Terra (iluminações) para o Sol $\left(E_{\mathrm{Sol}}\right)$ e para Sírio $\left(E_{\text {Sirio }}\right)$ será

$$
\frac{{ }^{\text {será }}}{E_{\text {Sol }}}=2,512^{\left(m_{\text {Sirio }}-m_{\text {Sol }}\right)}=2,512^{[-1.5-(-26,8)]}=2,512^{25,3} \text {, }
$$

ou seja,

$$
\frac{E_{\text {Sol }}}{E_{\text {Sirio }}}=1,320 \times 10^{10}
$$

Assim sendo, a lente necessária para poder queimar o papel com a luz de Sírio deveria ter uma área coletora $1,320 \times 10^{10}$ vezes maior do que aquela que queima um papel com a luz do Sol. E uma relação de áreas de $1,320 \times 10^{10}$ significa uma relação de diâmetros de $\sqrt{1,320 \times 10^{10}}=1,149 \times 10^{5}$. Logo, se a menor lente que permite incendiar um papel com relativa rapidez tiver $6 \mathrm{~cm}$ de diâmetro, usando a luz do Sol, a lente capaz de fazer o mesmo com a luz de Sírio deveria ter um diâmetro

$$
D^{\prime}=6 \times 1,149 \times 10^{5}=689348 \mathrm{~cm} \approx 6,893 \mathrm{~km} .
$$

À parte a dificuldade construtiva, e pondo de lado a dificuldade em arranjar tanto vidro, essa enorme lente com cerca de $6,9 \mathrm{~km}$ de diâmetro incendiaria o nosso papel, e convém saber que a relação focal da lente gigante seria a mesma da lente pequena (porque o fator de escala é linear), assegurando os nossos resulta$\operatorname{dos}^{(3)}$. O problema parece resolvido. Mas estará mesmo?

\section{Dificuldades inesperadas}

Sendo pequena a lente usada para o Sol, a sua espessura é pouco significativa, da ordem de $0,8 \mathrm{~cm}$. Quase não absorve radiação luminosa. Porém, ao passar para a "lente de Sírio", aumentamos essa lente cerca de $1,15 \times 10^{5}$ vezes em diâmetro, o que significa aumentar a sua espessura pelo mesmo fator, o que nos leva para uma espessura colossal de $0,8 \times 1,15 \times 10^{5} \mathrm{~cm}$, aproximadamente $90000 \mathrm{~cm}$ (ou seja, $0,9 \mathrm{~km}$ ). Como o vidro óptico mais vulgar, o crown $^{(4)}$ absorve cerca de $1 \%$ da radiação por cada centímetro de espessura (transmite 99\%). 


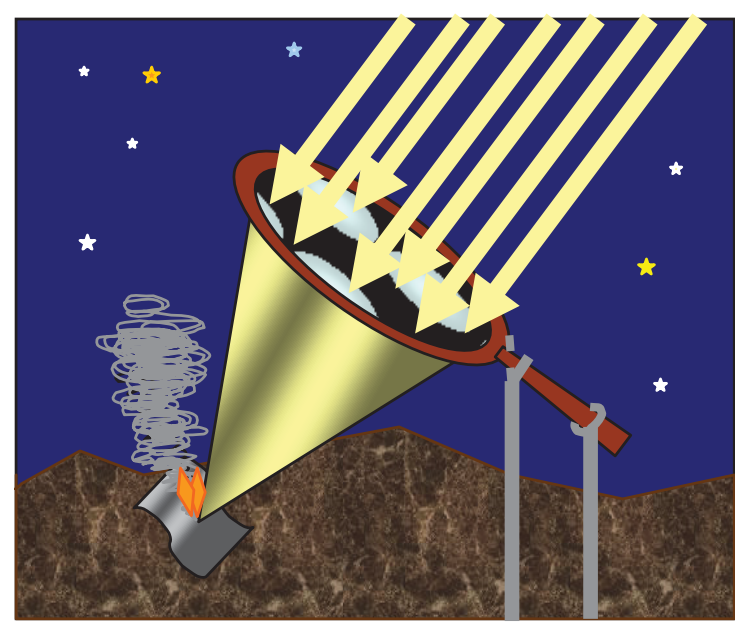

Fig. 2 - Uma lente colossal que resulta em uma solução impossível. Figura de Guilherme de Almeida, (2013).

Uma espessura de $90000 \mathrm{~cm}$ transmitirá

$$
0,99^{90000} \approx 1,47 \times 10^{-393} \text {, }
$$

ou seja, uns míseros $1,47 \times 10^{-391} \%$, ou ainda, dito de outra forma, apenas passará uma parte em $6,8 \times 10^{392}$. A lente seria praticamente opaca e, para melhor nos apercebermos disso, basta recordar que o filtro clássico para observação visual do Sol em luz branca transmite uma parte em $10^{5}$. Esta lente absorveria o equivalente a 79 filtros destes, colocados em série à passagem da luz. Perante isto, podemos desprezar justificadamente as perdas por reflexão na primeira e segunda superfícies dessa lente, que são de uns meros $5 \%$ por face. Sendo a lente praticamente opaca, apesar de ter a área coletora de luz necessária aos requisitos, é óbvio que não cumpriria os nossos objetivos, mesmo que pudesse ser construída. Esta solução revelase impossível.

Tudo isto para não falar na massa de vidro necessária para fabricar essa lente, que será $\left(1,15 \times 10^{5}\right)^{3} \approx 1,5 \times 10^{15}$ vezes superior à massa da lente pequena. Valendo esta última uns modestos $60 \mathrm{~g}$ (isto é, $0,060 \mathrm{~kg}$ ), a lente gigantesca teria, já pronta e desbastada, $0,060 \times 1,5 \times 10^{15} \mathrm{~kg}$, algo como 90 mil milhões de toneladas de vidro. Impossível segundo qualquer ponto de vista. 


\section{Uma solução possível, pelo menos em princípio}

Dada a impossibilidade funcional da lente acima referida, mesmo que fosse construída, por excessiva absorção da luz, resta a possibilidade de utilizar um enorme espelho paraboloidal. Esse espelho imenso precisaria ter os referidos 6,9 km de diâmetro, ou seja, um diâmetro 22,6 vezes superior ao do gigantesco radiotelescópio de Arecibo (que tem $305 \mathrm{~m}$ de diâmetro). Para dar uma perspectiva mais realista, convém sublinhar que, em um círculo de $6,3 \mathrm{~km}$ de diâmetro, cabem 5713 campos de futebol.

Não precisamos de nos preocupar com o diâmetro da imagem de Sírio no papel. Tal diâmetro nunca seria demasiado grande, pois o diâmetro aparente desta estrela é apenas 0,005936", ou seja, menos de 1/300 000 do diâmetro aparente do Sol (em rigor 1/303234).

Portanto, a imagem de sírio, focada no papel, seria sempre minúscula e na melhor das hipóteses determinada pela difração e não pelo diâmetro aparente de Sírio. O diâmetro do disco ${ }^{(5)}$ de difração $(\delta)$ da imagem de uma estrela, no plano focal de um sistema óptico convergente, para o comprimento de onda $\lambda$, vale

$$
\delta=\frac{2,44 \lambda f}{D}
$$

onde $f$ é a distância focal do espelho e $D$ o seu diâmetro (ALMEIDA, 2004).

A massa deste imenso espelho seria naturalmente colossal, não inferior à da lente acima referida (90 mil milhões de toneladas), exigindo recursos materiais imensos e dificuldades construtivas enormes. Se fosse possível construir esse espelho, incliná-lo apontando-o para Sírio e fazê-lo seguir esta estrela (outro desafio inesperado a ultrapassar, devido à sua enorme massa e dimensões), o sucesso seria garantido, contrariamente à lente de que falamos antes. De fato, uma aluminização recente apresenta um fator de reflexão de $88 \%$ seria eficaz, se pudesse ser construído.

\section{Refinando a solução, para uma conclusão mais realista}

$\mathrm{Na}$ verdade, apurando o cálculo, o espelho não precisará ser tão grande como acabamos de referir, pois (desprezando aberrações ópticas) a concentração de luz no plano focal será muito maior do que no caso do Sol, visto que o disco de Airy é muitíssimo menor do que o diâmetro da imagem solar. Supondo $f / D=2,5$ e $\lambda=550 \mathrm{~nm}=550 \times 10^{-9} \mathrm{~m}$, o diâmetro do disco de Airy valerá 


$$
\delta=2,44 \times 550 \times 10^{-9} \times 2,5 \mathrm{~m} \approx 3,36 \times 10^{-6} \mathrm{~m} .
$$

Como o que nos interessa é a intensificação da concentração de energia e vimos que se requer que tal fator valha (a exemplo do verificado no início deste artigo) 2094, que agora deverá ser ainda multiplicado por $1,320 \times 10^{10}$, que é a razão entre o fluxo luminoso que chega a cada $\mathrm{cm}^{2}$ do espelho exposta à luz do Sol relativamente ao que sucede com igual área do espelho, exposta à luz de Sírio, para que se obtenha a mesma concentração final de energia, no papel (como se mostra na Eq. 1). A área do espelho (desprezando perdas por reflexão) deverá ser $2094 \times 1,320 \times 10^{10}=2,764 \times 10^{13}$ vezes superior à do disco de Airy, ou seja, o diâmetro do espelho deverá ser

$$
D=\delta \sqrt{2,764 \times 10^{13}} \approx 5,26 \times 10^{6} \delta,
$$

o que nos conduziria a

$$
D=\approx 17,8 \mathrm{~m} \text {. }
$$

Antes que nos entusiasmemos, empolgados com este resultado ideal, convém saber que a turbulência atmosférica, fazendo variar rapidamente a direção dos raios luminosos, espalha-os no plano focal segundo um disco que raramente corresponderá a menos de 2" de diâmetro aparente no céu (correspondendo a resoluções da ordem de 1"), o que já nos coloca, por efeito da turbulência, na situação de fonte extensa, pelo que deveremos refazer o cálculo para um diâmetro aparente de $2 "\left(2 "=9,70 \times 10^{-6} \mathrm{rad}\right)$ e já não para o disco de Airy. Por exemplo, para um espelho de 5 metros de distância focal, o disco de difusão no plano focal apresenta um diâmetro $d "$, de

$$
d^{\prime \prime}=9,70 \times 10^{-6} \mathrm{rad} \times \mathrm{f}=9,70 \times 10^{-6} \times 5 \mathrm{~m}=4,85 \times 10^{-5} \mathrm{~m} .
$$

Para assegurar a concentração de energia requerida, o diâmetro do espelho deverá ter $5,26 \times 10^{6}$ vezes superior a este, ou seja, valerá

$$
D^{\prime \prime}=5,26 \times 10^{6} \times 4,85 \times 10^{-5} \mathrm{~m} \approx 255 \mathrm{~m} .
$$

Como um espelho aluminizado apenas reflete $88 \%$ do fluxo luminoso nele incidente, precisaremos fazê-lo um pouco maior, com o diâmetro $D$ "' $>D$ ", para compensar as perdas por reflexão e obter a concentração final de energia que desejamos. A sua nova área deverá ser $1 / 0,88 \approx 1,14$ vezes maior e o novo diâmetro ${ }^{(6)}$, deverá ser 


$$
D^{\prime \prime \prime}=\sqrt{1,14} D^{\prime \prime} \approx 1,07 D^{\prime \prime}
$$

Obtemos, então, $D "=1,07 \times 255 \approx 273 \mathrm{~m}$.

Este espelho, embora já não seja tão gigantesco como o do primeiro cálculo, precisaria ter uma distância focal muitíssimo pequena em relação ao seu diâmetro. Ou seja, uma relação focal $f / D=5 / 273 \approx 0,018$. Seria extremamente "cavado" e praticamente impossível de construir. Para dar uma ideia concreta, basta referir que os espelhos de relação focal mais curta, que se fazem para telescópios, têm $f / D=2$. Não nos adianta aumentar-lhe a distância focal, pois o diâmetro do disco de maior concentração de energia aumentaria na mesma proporção (Cf. Eq. 4), o que, por sua vez, iria obrigar-nos a aumentar o diâmetro do espelho de igual modo (Cf. Eq. 5).

Se fosse possível construir este espelho, ultrapassando todos os fatores complicativos no plano construtivo, seria finalmente possível queimar o tal papel à luz cintilante de Sírio, em uma noite quente de Verão (para um observador situado no hemisfério Sul).

\section{Referências bibliográficas}

ALMEIDA, G. de Telescópios. Lisboa: Plátano Editora, 2004.

FERREIRA, M.; ALMEIDA, G. de Introdução à Astronomia e às observações astronômicas. 7. ed. Lisboa: Plátano Editora, 2004.

HECHT, E. Óptica. 2. ed. Lisboa: Fundação Calouste Gulbenkian, 2002.

\footnotetext{
(1) Um parâmetro útil é a relação focal $f / D$, quociente da distância focal da lente pelo diâmetro, expressos nas mesmas unidades. Neste exemplo, com $f=15 \mathrm{~cm} \mathrm{e} D=6 \mathrm{~cm}$, $f / D=15 / 6=2,5$. No caso de fontes luminosas não pontuais (como é o caso do Sol), e para uma dada fonte, a concentração de luz no plano focal é inversamente proporcional ao quadrado de $f / D$. Como é óbvio, esta grandeza é adimensional.

(2) Sírio ( $\alpha$ do Cão Maior) é a estrela de maior brilho aparente em todo o céu, a seguir ao Sol. Trata-se, portanto, da mais forte candidata, a seguir ao Sol, à experiência conceptual que pretendemos desenvolver. É uma das estrelas mais próximas de nós (está a 8,7 anos-luz) e é intrinsecamente 21 vezes mais brilhante do que a nossa estrela. Note-se que a distância de 8,7 anos-luz é 550000 vezes maior do que a distância média da Terra ao Sol.
} 
(3) Em rigor, deveríamos incluir o diâmetro aparente de Sírio (visto da Terra) nos nossos cálculos. No entanto, tal diâmetro aparente, ou diâmetro angular é incrivelmente pequeno: 0,005936", ou seja, aproximadamente 1/300 000 do diâmetro aparente do Sol. Nesse caso, a imagem de Sírio não será resolvida no plano focal da lente, pois o disco de Airy será muito maior do que a hipotética imagem de Sírio no plano focal. Assim sendo, e desprezando aberrações ópticas, a luz de Sírio iria concentrar-se num pequeno disco iluminado com o diâmetro do disco de Airy (e uma parte ainda menor, que desprezaremos, nos anéis de difração). Como a lente é praticamente opaca, o problema deixa de ser colocar. Mas retomaremos a questão mais adiante, na hipótese de usar um espelho côncavo.

(4) $\mathrm{O}$ vidro crown é o tipo de vidro mais comum usado em lentes e outros componentes ópticos. Tem um índice de refração relativamente baixo, tipicamente próximo de 1,52 e baixa dispersão (a velocidade de propagação da luz nesse vidro, para a luz de diferentes cores, apresenta uma diferença menos acentuada do que para outros tipos de vidro). A indicação da reflexão da luz em uma superfície de vidro nua e a explicação detalhada do poder dispersivo de um vidro podem ser vistas na obra de Hecht, 2002, citada nas referências bibliografias. O conceito de índice de refração pode ser encontrado em Almeida, 2004, e na obra de Hecht, já referida.

(5) Mais rigorosamente o diâmetro do primeiro anel escuro da figura de difração. O conceito é abordado em Almeida, 2004.

(6) $\mathrm{O}$ leitor interessado pode refazer o cálculo relativo à lente, para o caso de Sírio, tendo em conta o novo diâmetro da área de máxima concentração de luz, com ou sem turbulência (calculando para os diâmetros referidos). Chegará à conclusão de que essa lente teria um fator de transmissão tão baixo que ainda seria praticamente opaca. 